\title{
A shortened scheme for the identification of indifferent streptococci
}

\author{
SHEENA A WAITKINS, LYN C BALL, AND CHERRY AM FRASER \\ From the Division of Hospital Infection, Central Public Health Laboratory, London NW9 5HT, UK
}

SUMMARY A shortened biochemical scheme was devised for the reliable identification of the 'viridans' streptococci. It compared favourably with the classical identification system of Colman and could be recommended for use in the busy routine laboratory to investigate streptococcal isolates from clinical sources.

The classification of streptococci has increased in complexity from early comprehensive classifications such as that of Brown. ${ }^{1}$ Sherman ${ }^{2}$ placed the various species of streptococci into one of four divisions and named these divisions 'pyogenic, 'viridans', 'lactic', and 'enterococci'. Since then the classification of streptococci other than the recognised 'pyogenic' Lancefield groups has until recently been of little interest. Colman ${ }^{3}$ and Colman and Williams ${ }^{4}$ in 1970 and 1972 examined a collection of haemolytic and non-haemolytic streptococci by means of a long complex range of biochemical and physiological tests. This range of tests was shortened by Parker and Ball, ${ }^{5}$ who found that most of the isolates were classifiable by this means of identification. Despite this shortened range of tests, classification of the $\alpha$ and non-haemolytic streptococci was still a long, time-consuming procedure and therefore made this type of classification an impossible task to perform easily in a routine, busy laboratory.

By selecting ' $k e y$ ' biochemical tests from the range already in use by Parker and Ball, ${ }^{5}$ and adapting them to solid media in plate tests, we were able to reduce the number of tests required by half (see Table 1). The physiological tests for preliminary identification of $\alpha$ and non-haemolytic streptococci were not altered as these were the main criteria for primary classification. This shortened biochemical system was run in parallel with the longer identification scheme as outlined by Parker and Ball ${ }^{5}$ and found to give good overall correlation with it; most of the streptococci could be placed in a recognised taxon.

The selection of these 'key' biochemical tests, the simplicity of preparing the media, and the ease with which the biochemical tests themselves could be carried out are discussed in this paper.

Received for publication 9 July 1979

\section{Material and methods}

ORG A N ISM S

These were either selected from the routine strains that were sent to the Division of Hospital Infection, Colindale, for routine identification or were NCTC strains.

\section{CULTURAL METHODS}

All cultures were examined microscopically by Gram-stained films; the colonial appearance and presence or absence of haemolysis were recorded after incubation overnight at $37^{\circ} \mathrm{C}$ on blood agar plates (Hartley digest agar ${ }^{6}$ containing $5 \%(\mathrm{v} / \mathrm{v})$ of defibinated horse blood and layered over peptone water agar). Haemolysis and morphological growth in aerobic, anaerobic, and $\mathrm{CO}_{2}$ atmospheres were noted as described by Parker and Ball. ${ }^{5}$

\section{BIOCHEMICAL METHODS}

\section{Long sets}

The methods used were those described by Parker and Ball. ${ }^{5}$

\section{Short identification sets}

All media used in these short sets with the exception of polysaccharide production were dispensed in $2 \mathrm{ml}$ amounts into Baird-Parker replica plates (Sterilin Products, England). The plates were allowed to solidify and were then dried for 1 hour before use. Twenty strains per plate could be tested at any one time, and controls of four different streptococci were included to make a total of 24 tested. One space was left blank to serve as a media sterility control. Media plates can be stored without deterioration of substrate for up to one month at $4^{\circ} \mathrm{C}$. 
Table 1 Scheme for recognition of species by short set system

\begin{tabular}{|c|c|c|c|c|c|c|c|c|c|c|c|c|c|}
\hline & 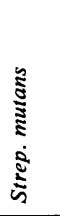 & 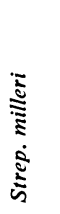 & 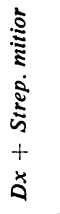 & 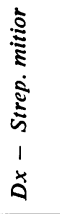 & 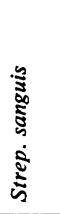 & 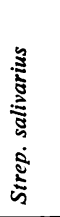 & 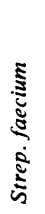 & 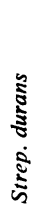 & $\begin{array}{l}\bar{y} \\
: \overline{0} \\
\dot{8} \\
\dot{8} \\
\dot{5}\end{array}$ & 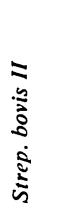 & 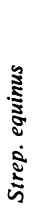 & 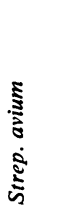 & 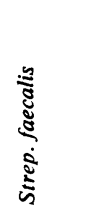 \\
\hline Lactose & + & $\stackrel{+}{(86)}$ & + & $\stackrel{+}{(88)}$ & $\begin{array}{l}+ \\
\text { (99) }\end{array}$ & + & + & + & + & $\stackrel{+}{(96)}$ & - & + & $\begin{array}{c}+ \\
(99)\end{array}$ \\
\hline Raffinose & $\begin{array}{l}+ \\
(96)\end{array}$ & - & $\stackrel{+}{(81)}$ & - & - & $\stackrel{+}{(71)}$ & - & - & $\begin{array}{l}+ \\
(97)\end{array}$ & $\begin{array}{l}+ \\
(92)\end{array}$ & - & - & - \\
\hline Arabinose & - & - & - & - & - & - & + & - & - & - & - & + & - \\
\hline Sorbitol & $\begin{array}{l}+ \\
(91)\end{array}$ & - & - & - & - & - & - & - & - & - & - & - & $\stackrel{+}{(89)}$ \\
\hline Mannitol & + & - & - & - & - & - & + & - & $\begin{array}{l}+ \\
(94)\end{array}$ & - & - & + & $\begin{array}{l}+ \\
(98)\end{array}$ \\
\hline Aesculin & $\begin{array}{l}+ \\
(93)\end{array}$ & $\stackrel{+}{(78)}$ & - & - & $\stackrel{+}{(84)}$ & - & + & + & $\begin{array}{l}+ \\
(97)\end{array}$ & + & - & + & + \\
\hline $6.5 \% \mathrm{NaCl}$ & - & - & - & - & - & - & + & + & - & - & - & + & + \\
\hline Dextran & $\begin{array}{l}+ \\
(98)\end{array}$ & - & + & - & $\stackrel{+}{(72)}$ & - & - & - & $\stackrel{+}{(94)}$ & - & - & - & - \\
\hline Laevan & - & - & - & - & - & + & - & - & - & - & - & - & - \\
\hline Arginine & - & $\stackrel{+}{(86)}$ & - & - & $\begin{array}{l}+ \\
(91)\end{array}$ & - & + & + & - & - & - & - & $\begin{array}{l}+ \\
(96)\end{array}$ \\
\hline VP & $\stackrel{+}{(82)}$ & $\begin{array}{l}+ \\
(86)\end{array}$ & - & - & - & - & + & - & $\begin{array}{l}+ \\
(96)\end{array}$ & $\begin{array}{l}+ \\
(96)\end{array}$ & - & + & $-\overline{(67 \%+)}$ \\
\hline Starch & - & - & - & - & - & - & - & - & + & - & - & - & - \\
\hline Pyruvate & - & - & - & - & - & - & - & - & - & - & - & $+^{*}$ & + \\
\hline $10 \%$ Bile & + & - & - & - & - & - & + & + & $\begin{array}{l}+ \\
(96)\end{array}$ & + & + & + & + \\
\hline $40 \% \mathrm{Bil}=$ & + & - & - & - & - & - & + & + & $\begin{array}{l}+ \\
(98)\end{array}$ & + & + & + & + \\
\hline
\end{tabular}

* Positive after 72 hours.

\section{INOCULUM}

A well isolated colony was micro-picked from any of the aerobic/anaerobic or $\mathrm{CO}_{2}$ plates and inoculated into Todd-Hewitt broth. This was then incubated overnight, the turbid growth was checked for purity, and each division of the media received one drop from a Pasteur pipette.

MEDIA

$\begin{array}{cr}\text { 'Sugar'* fermentation tests } & \\ \text { Difco Yeast Extract } & 5 \mathrm{~g} \\ \text { Difco Tryptone } & 10 \mathrm{~g} \\ \text { Agar } & 5 \mathrm{~g} \\ \text { Distilled water } & 500 \mathrm{ml}\end{array}$

Autoclave $10 \mathrm{lb}$ for 10 minutes. When cool add aseptically sterile $10 \%$ litmus blue solution and $10 \%$ sugar to substrate, making a final concentration of $0.4 \%$ litmus blue and $1 \%$ sugar.The $\mathrm{pH}$ was adjusted to 7.0. Results were recorded after five days' incubation at $37^{\circ} \mathrm{C}$ in a $5 \% \mathrm{CO}_{2}$ atmosphere. A positive reaction was indicated by a red colouring of the medium while a negative result remained blue.

*Aesculin was added before autoclaving, because it is difficult for this sugar to form a solution at room temperature.
Although litmus blue solution was used as a $\mathrm{pH}$ indicator in this medium, any $\mathrm{pH}$ indicator, for example, phenol red, may be substituted.

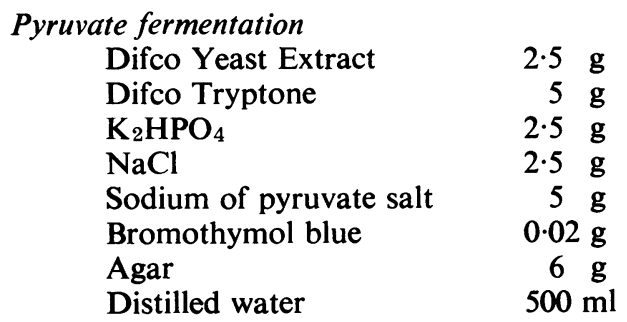

The mixture was heated gently until all the ingredients were dissolved, $\mathrm{pH}$ was then readjusted to $7 \cdot 2$, and sterilised by autoclaving at $15 \mathrm{lb} / \mathrm{in}^{2}$ for $15 \mathrm{~min}-$ utes.

A positive reaction was indicated by a yellow coloration after 24 to 48 hours.

\section{Salt toleration $(6.5 \%)$}

Nutrient Broth No. 2

$\mathrm{NaCl}$

Agar

$500 \mathrm{ml}$

$5 \mathrm{~g}$

The mixture was heated gently and, when the ingredients had dissolved, it was sterilised by autoclaving at $15 \mathrm{lb} / \mathrm{in}^{2}$ for 15 minutes. Just before dis- 
Table 2 Comparison, test for test, used in the long and short set identification scheme

\begin{tabular}{|c|c|c|c|c|c|}
\hline & \multicolumn{4}{|c|}{ Total number of strains $=156$} & \multirow[t]{2}{*}{ Total } \\
\hline & $\begin{array}{l}\text { Long set }+v e \\
\text { Short set }+v e\end{array}$ & $\begin{array}{l}\text { Long set }-v e \\
\text { Short set }-v e\end{array}$ & $\begin{array}{l}\text { Long set }+v e \\
\text { Short set }-v e\end{array}$ & $\begin{array}{l}\text { Long set }-v e \\
\text { Short set }+v e\end{array}$ & \\
\hline $6.5 \% \mathrm{NaCl}$ & 5 & 129 & 13 & 9 & 156 \\
\hline Aesculin hydrolysis & 38 & 96 & 4 & 13 & 151 \\
\hline $40 \%$ Bile & 41 & 79 & 11 & 24 & 155 \\
\hline $10 \%$ Bile & 50 & 13 & 8 & 81 & 152 \\
\hline VP & 100 & 35 & 10 & 8 & 153 \\
\hline Arginine & 88 & 60 & 6 & 3 & 157 \\
\hline Lactose & 128 & 14 & 6 & 3 & 151 \\
\hline Mannitol & 38 & 105 & 1 & 4 & 148 \\
\hline Aesculin & 105 & 24 & 14 & 8 & 151 \\
\hline Raffinose & 56 & 73 & 13 & 9 & 151 \\
\hline Arabinose & 1 & 155 & $\mathbf{0}$ & 0 & 156 \\
\hline Sorbitol & 5 & 150 & 1 & $\mathbf{0}$ & 156 \\
\hline
\end{tabular}

pensing into plates, $0.5 \%$ sterile glucose was added, and the final $\mathrm{pH}$ was $7 \cdot 0$. Incubation was for five days and growth indicated tolerance.

$\begin{array}{llc}\text { Growth on bile salts } & 10 \% & 40 \% \\ \text { Oxoid Nutrient Agar } & 500 \mathrm{ml} & 500 \mathrm{ml} \\ \text { Difco Dehydrated 10\% } & 5.25 \mathrm{~g} & 21 \mathrm{~g} \\ \text { Ox Gall }(0128-01) & & \end{array}$

Ox Gall (0128-01)

These were heated gently and when the ingredients were dissoived it was sterilised by autoclaving at $15 \mathrm{lb} / \mathrm{in}^{2}$ for 15 minutes. Just before being dispensed $25 \mathrm{ml}$ of sterile Horse Serum (Oxoid) was added. Bile tolerance was indicated by growth on the plate after 24 hours' incubation.

$\begin{array}{lr}\begin{array}{l}\text { Arginine dihydrolase } \\ \text { Difco Yeast Extract }\end{array} & 2.5 \mathrm{~g} \\ \text { Difco Tryptone } & 2.5 \mathrm{~g} \\ \mathrm{~K}_{2} \mathrm{HPO}_{4} & 1 \mathrm{~g} \\ \text { L-Arginine-monohydrochloride } & 1.5 \mathrm{~g} \\ \text { Agar } & 5 \mathrm{~g} \\ \text { Distilled water } & 500 \mathrm{ml}\end{array}$

The mixture was heated gently until all the ingredients had dissolved and was then sterilised by autoclaving at $15 \mathrm{lb} / \mathrm{m}^{2}$ for 15 minutes. Cultures were incubated for five days, after which time the production of ammonia from arginine was tested by running $1 \mathrm{ml}$ of Nesslers reagents on to each sample. A positive reaction gave a vivid orange colour, while a negative reaction remained green/yellow.

$\begin{array}{lr}\text { Voges-Proskauer }(V P) \text { test } & \\ \text { Difco Yeast Extract } & 2.5 \mathrm{~g} \\ \text { Difco Tryptone } & 5 \mathrm{~g} \\ \mathrm{~K}_{2} \mathrm{HPO}_{4} & 2 \cdot 5 \mathrm{~g} \\ \text { Agar }_{\text {Distilled water }}^{5} \mathrm{~g} \\ & 500 \mathrm{ml}\end{array}$

The mixture was heated gently until all the ingredients had dissolved, and then autoclaved at $15 \mathrm{lb} / \mathrm{in}^{2}$ for 15 minutes. Just before dispensing $0.5 \%$ sterile glucose was added and the final $\mathrm{pH}$ was $7 \cdot 0$. Cultures were incubated for five days, after which the VP reaction was performed by a modification of Barritt's method, as described below:

\section{$V P$ reagents and test method \\ $20 \mathrm{ml} 6 \%$ a naphthol in absolute alcohol \\ $12 \mathrm{ml} 40 \% \mathrm{KOH}$ \\ Added together just before use} $0.5 \mathrm{ml}$ amounts of this mixture were then added to each culture, and development of the reaction occurred at $37^{\circ} \mathrm{C}$ until a known positive control had developed its full colour intensity. A positive reaction was indicated by red coloration and a negative reaction failed to change colour.

\section{Starch hydrolysis Oxoid Blood Agar Base \\ Soluble starch \\ $500 \mathrm{ml}$ \\ $1 \mathrm{~g}$}

These were heated gently until they were thoroughly mixed, then autoclaved at $15 \mathrm{lb} / \mathrm{in}^{2}$ for 15 minutes. The starch plates were incubated for 24-48 hours, after which they were tested for starch hydrolysis by pouring $0.5 \mathrm{ml}$ of Lugol's iodine on to each culture. A positive starch hydrolysis was detected by a bright yellow coloration of the agar.

\section{Production of extracellular polysaccharide from sucrose}

Cultures were grown in Bailey and Oxford's ${ }^{7,8}$ medium for five days and tested for the production of dextran and levan by differential precipitation with ethanol, as described by Hehre and Neill ${ }^{9}$-for details see Colman and Williams. ${ }^{4}$

Serological tests and survival at $60^{\circ} \mathrm{C}$ for 30 minutes These were carried out as described by Parker and Ball. 5

Both the long and short sets were incubated at $37^{\circ} \mathrm{C}$ in a $\mathrm{CO}_{2}$ incubator $\left(5 \% \mathrm{CO}_{2}\right.$ in air); incubation times varied according to the biochemical test used. 
Table 3 Percentage of results that conform to the classical pattern for streptococcal species identification

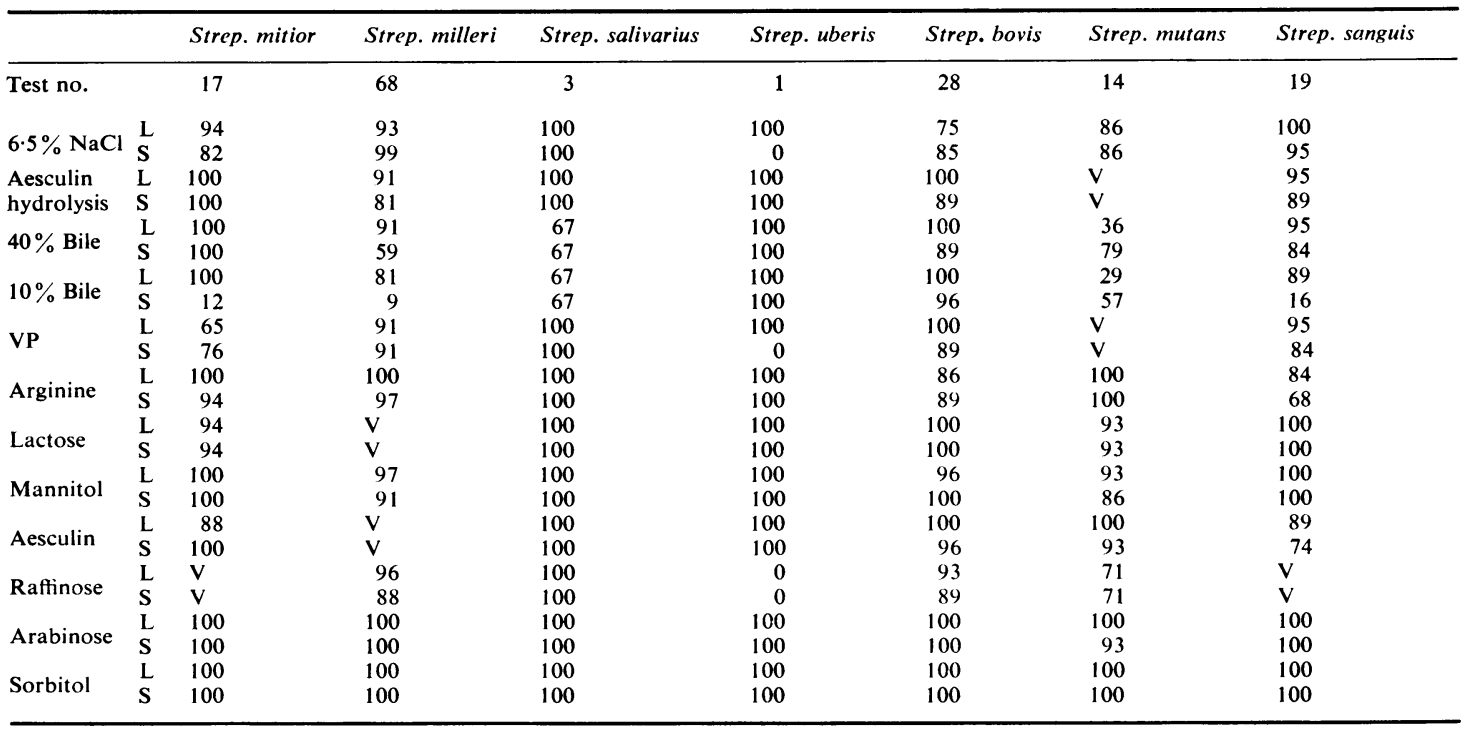

V : variable

\section{Results}

The performances of both long and short identification sets were compared with each other using routine streptococcal strains as well as selected reference strains from the National Collection of Type Cultures. These have been fully described in
Material and methods. The biochemical tests used for recognition of streptococci in the short sets were those shown in Table 1. The results of these comparisons are summarised in Tables 2 to 5 . Table 2 illustrates our findings when each individual test, from both the long and short set systems, are compared with each other. There is good overall cor-

Table 4 Percentage of results that conform to the classical pattern for streptococcal NCTC species identification

\begin{tabular}{|c|c|c|c|c|c|c|c|c|}
\hline & & Strep. mitior & Strep. milleri & Strep. mutans & Strep. faecalis & Strep. faecium & Strep. sanguis & Strep. salivarius \\
\hline Test no. & & 1 & 2 & 1 & 11 & 4 & 4 & 1 \\
\hline \multirow{2}{*}{$6.5 \% \mathrm{NaCl}$} & $\mathbf{L}$ & 100 & 100 & 100 & 100 & 100 & 100 & 100 \\
\hline & $\mathbf{S}$ & 100 & 100 & 100 & 100 & 100 & 100 & 100 \\
\hline \multirow{2}{*}{$\begin{array}{l}\text { Aesculin } \\
\text { hydrolysis }\end{array}$} & $\mathbf{L}$ & 100 & 100 & 100 & 100 & 100 & 100 & 100 \\
\hline & $\mathbf{S}$ & 100 & 100 & 100 & 100 & 100 & 100 & $100^{\circ}$ \\
\hline $40 \%$ Bile & $\mathbf{L}$ & 100 & 100 & 0 & 100 & 100 & 100 & 100 \\
\hline \multirow{2}{*}{$10 \%$ Bile } & L & 100 & 50 & 0 & 100 & 100 & 100 & 100 \\
\hline & $\mathbf{S}$ & 100 & 0 & 100 & 100 & 100 & 0 & 0 \\
\hline \multirow{2}{*}{ VP } & $\mathrm{L}$ & 100 & 100 & 100 & 100 & 100 & 100 & V \\
\hline & $\mathbf{S}$ & 100 & 100 & 100 & 100 & 100 & 100 & V \\
\hline \multirow{2}{*}{ Arginine } & $\mathbf{L}$ & 100 & 100 & 100 & 100 & 100 & 100 & 0 \\
\hline & $\mathbf{S}$ & 100 & 100 & 100 & 100 & 100 & 100 & 100 \\
\hline \multirow{2}{*}{ Lactose } & $\mathbf{L}$ & 100 & 100 & 100 & 100 & 100 & 100 & 100 \\
\hline & $\mathbf{S}$ & 100 & 100 & 100 & 100 & 100 & 100 & 100 \\
\hline Mannitol & $\mathbf{L}$ & 100 & 100 & 100 & 100 & 100 & 100 & 100 \\
\hline Aesculin & $\mathbf{S}$ & 100 & 100 & 100 & 100 & 100 & 100 & 100 \\
\hline \multirow{2}{*}{ Raffinose } & $\mathbf{L}$ & V & 100 & 100 & 100 & 100 & V & 100 \\
\hline & $\mathbf{S}$ & V & 100 & 100 & 100 & 100 & V & 100 \\
\hline \multirow{2}{*}{ Arabinose } & $\mathbf{L}$ & 100 & 100 & 100 & 100 & 100 & 100 & 100 \\
\hline & $\mathbf{S}$ & 100 & 100 & 100 & 100 & 100 & 100 & 100 \\
\hline \multirow{2}{*}{ Sorbitol } & $\mathbf{L}$ & 100 & 100 & 100 & 100 & 100 & 100 & 100 \\
\hline & $\mathbf{S}$ & 100 & 100 & 100 & 100 & 100 & 100 & 100 \\
\hline
\end{tabular}

$\mathrm{V}=$ variable 
Table 5 Number of strains fully identified by the long and short set system

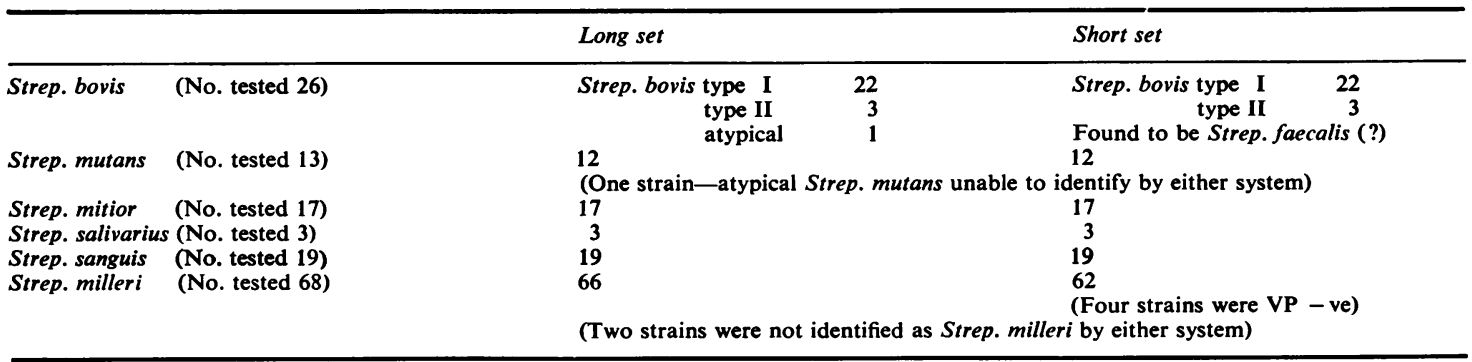

relation of positive and negative results in almost all of the tests examined, with the exception of $10 \%$ bile tolerance, in the short sets, which varied consistently from those classical results recorded by the long sets. This variation may be due to several factors, including ease of reading the bile tolerance in the short set system, and media composition which is probably the primary cause for the increased positive results recorded by the short sets ( 81 'false' positives, cf, long sets).

Table 3 deals with the comparison of tests within each streptococcal strain from the routine. Here again, the correlation between long and short sets is good, and again $10 \%$ bile tolerance is consistently at variance within these two systems. It can be noted from the types of strains commonly found in our routine clinical specimens that Strep. milleri accounts for almost half our isolates (68/156), while Strep. uberis and Strep. salivarius between them total only 4 out of 156 ( $2.5 \%$ total number). Strep. faecalis is routinely identified by survival at $60^{\circ} \mathrm{C}$ for 30 minutes and pyruvate fermentation; therefore it is normally not subjected to full long set identification. This explains why Strep. faecalis is not included in Table 3. However, the comparison of each test with NCTC strains of Strep. faecalis can be seen in Table 4 which will be described below.

The long and short set tests in Table 3 show that the variation of the actual test is recorded in both systems, for example, Strep. mutans has been shown to vary in its ability to produce acetylmethylcarbinal, and therefore its detection in the Voges-Proskauer (VP) reaction gives variable results which are seen in both long and short sets. It must be pointed out that no matter how good the short set system proves to be it cannot be better than the long set as we use this in our determination of the 'classical pattern'. Therefore, to some extent there is a bias towards the performance of the long sets, particularly when the strains under test are unknown routine strains, the history of which may be very limited, and the testing of the strain only once in the long set.
A better comparison of these biochemical tests from the long and short sets can be seen in Table 4 where the strains that we have used are all wellknown, recorded NCTC strain streptococci. The overall pattern of good correlation persists in Table 4. The numbers that we tested were small, but nevertheless it served to show us that the long and short sets were comparable. Strep. faecalis was the only significant organism in this table as we did not test any in the routine strains. The biochemical convenience of the short sets illustrated itself very effectively because, although not recorded in Table 4, the pyruvate fermentation was much easier to perform than tetrazolium reduction. ${ }^{10}$

Finally, Table 5 summarises our findings with the routine strains that were used in this study. Strep. bovis could be divided into its biotypes I and II in the long sets by its mannitol fermentation and dextran production, but in $6 \%$ of Strep. bovis biotype I it can be mischaracterised to biotype II (see Table 1). In the short set system the hydrolysis of starch is used for the reasons outlined in the introduction, thus avoiding this identification error. As can be seen, the long sets identified 21 type I and 3 type II, as did the short sets. One atypical type of Strep. bovis was classified as Strep. faecalis by pyruvate fermentation in the short set system. On further investigation this was indeed confirmed by repeating the reduction of tetrazolium in the long sets. Strep. mutans, Strep. mitior, Strep. salivarius, and Strep. sanguis gave complete correlation with both sets. Four Strep. milleri strains proved to be VP negative in the short set system and would therefore not have been fully identified.

\section{Discussion}

As we outlined in the introduction, the manual labour involved in preparing and performing the long set system is considerable, and the normal busy routine laboratory cannot hope to handle the various types of biochemical tests currently required fully 
to identify streptococcal species isolated from clinical specimens. This study was undertaken for two reasons: the ease of utilising a short set system would encourage routine laboratories positively to identify their own streptococcal specimens and would also enable the reference laboratory to process large numbers of samples from epidemiological surveys with ease and certainty of identification.

Tables 2 to 5 illustrate how well the short set identification system compares with the long set currently in use. On the whole, this comparison favoured the use of the short set system, and identification of streptococci could be just as correctly attained by it. There are some points that are worth noting in the performance of the short set system. Firstly, the composition of the scheme, as was mentioned in the introduction, had to be shortened in number from the existing classical long sets used. The exclusion of many of the long set tests was due to their lack of discrimination in identification. For example, dulcitol was negative for all streptococci tested, while sucrose was consistently positive. The 'key tests', as outlined in Table 1, were drawn from the experiences obtained during the epidemiology survey carried out by Parker and Ball. ${ }^{5}$ However, the exclusion of some of the tests, for example, the reduction of tetrazolium, rested with the knowledge obtained that tetrazolium reduction by Strep. faecalis varied with the batches of 2-3-5 triphenyltetrazolium chloride, leading to equivocable results being recorded. It was also noted that rare strains of Strep. faecium possessed the ability to reduce tetrazolium, thereby being classified as a 'false' Strep. faecalis. ${ }^{10}$ These problems were overcome by employing the fermentation of pyruvate by Strep. faecalis as a specific test for this organism, and thereby excluding Strep faecium, which lacked this ability, even in those strains that could reduce tetrazolium.

Even when the 'key tests' had been agreed, the media of the long sets still excluded routine use by normal laboratories with simple media facilities. Preparation of Hiss serum water sugars was the main obstacle for many would-be users, so the serum was substituted with a highly proteinaceous medium, mainly of tryptone and yeast extract. This facilitated direct sterilisation by autoclaving. The composition of the short sets was then tested and compared to currently used long sets, and the results were analysed as reported in the Results section. Tables 3 and 4 illustrate the overall compatibility of both systems but, as was mentioned in the Results section, there is a bias towards the long sets because these have always been used as our classification criteria for identification of the streptococci. Notwithstanding this prejudice against the short sets, they compare very favourably with the long set results in almost all the tests used with the exception of $10 \%$ bile tolerance. This variation is most certainly due to the excessively rich basal medium and, perhaps a little, to the ease of reading. In all the strains tested, only four Strep. milleri proved to be difficult to identify fully using the short set system, and for those we recommend full identification by long sets.

In conclusion, the basal medium for the short set system is easy to prepare and can be dispensed into bottles or Baird-Parker replica plates for larger numbers. Contamination can be easily recognised, thereby eliminating the need for purity plates, and a range of atmospheric conditions for incubation can easily be achieved. Finally, the number of tests required to identify most streptococci is within the routine abilities of most laboratories.

\section{References}

${ }^{1}$ Brown $\mathrm{J} \mathrm{H}$. The use of blood agar for the study of streptococci. Monogr Rockefeller Inst Med Res $1919 ; 9$.

${ }^{2}$ Sherman J M. The streptococci. Bact Revs 1937; 1: 3-97.

${ }^{3}$ Colman G. The classification of streptococcal strains. PhD Thesis, University of London 1970.

${ }^{4}$ Colman G, Williams R E O. Taxonomy of some human viridans streptococci. In: Wannamaker $\mathrm{L} W$, Matsen J M, eds. Streptococci and Streptococcal Diseases. Recognition Understanding and Management. New York and London: Academic Press, 1972: 281-299.

${ }^{5}$ Parker M T, Ball L C. Streptococci and aerococci associated with systemic infection in man. $J$ Med Microbiol 1976; 9: 275-302.

${ }^{6}$ Cowan S T, Steel K J. Manual for the Identification of Medical Bacteria: 2nd ed, Cowan S T, ed. London: Cambridge University Press, 1974.

${ }^{7}$ Bailey R W, Oxford A E. A quantitative study of the production of dextran from sucrose by rumen strains of Streptococcus bovis. J Gen Microbiol 1958; 19: 130-145.

${ }^{8}$ Bailey R W, Oxford A E. Pre-requisites for dextran production by Streptococcus bovis. Nature 1958; 182: $185-186$.

${ }^{9} \mathrm{Hehre}$ E J, Neill J M. Formation of serologically reactive dextrans by streptococci from sub-acute bacterial endocarditis. J Expt Med 1946; 83: 147-162.

${ }^{10}$ Waitkins S A. Use of pyruvate fermentation compared with tetrazolium reduction in the differentiation of group D streptococci. J Clin Pathol 1978; 31 : 692-695.

Requests for reprints to: Dr Sheena A Waitkins, Regional Public Health Laboratory, Fazakerley Hospital, Lower Lane, Liverpool L9 7AL, UK. 
hensive review is most welcome. Immunological Aspects of Infectious Diseases provides a well-written, multiauthored book on the subject, from basics on specific and non-specific defence against infection, to most recent research on the immunopathology of viral, bacterial, fungal and protozoal infections.Interesting reviews on the relation between infections and allergy, autoimmunity, tissue damaging immune complexes as well as granulomatous lesions are presented. Some overlapping between the chapters may be inevitable, but two chapters on immunodeficiency seems unnecessary. A few minor deficiencies exist such as the reference to clinical effects of transfer factor treatment, although such are not well supported by controlled studies. Likewise, the role of $\mathrm{Zn}$ in certain immunodeficiencies is not mentioned.

This up-to-date book should find readers among medical students as well as practitioners and researchers.

L. A. HANSON

Essentials of Neuropathology. By S. S. Schochet and W. F. McCormick. (Pp. vii +191 ; illustrated; $£ 8.40, \$ 16.85$.) Hemel Hempstead: Prentice/Hall International. 1979.

It is always a difficult task to condense a large subject like neuropathology into a slim manual of 190 pages. Drs Schochet and McCormick have succeeded in many respects in producing an informative summary of the major diseases of the nervous system. The first section of the book on basic neuropathology is a good introduction to methods of sampling and staining postmortem brains in addition to a well-arranged summary of major neural and pathological structures. The section on malformations and perinatal lesions is followed by the two best chapters in the book: those on trauma and infections. Cerebrovascular disease, metabolic disorders, intoxications, tumours, dementias, and demyelinating diseases are briefly covered. The book ends with sections on disorders of peripheral nerve and muscle. Inevitably there are defects; perhaps the most obvious is the lack of significant clinical details which would be very helpful to pathologists. For most readers, I would suspect, there is an uncomfortable concentration of eponymous terms, many of which are not used in Britain.

The book is fine but the description of its contents on the back cover is almost completely untrue and may lead to disappointment for the unwary purchaser. It is not a substitute for the larger textbooks necessary for diagnostic neuropathology but forms a concise, wellwritten, and illustrated introduction to the field of neuropathology.

R. O. WELLER

Burns. A Team Approach. By C. P. Artz, J. A. Moncrief and B. A. Pruitt. (Pp. xi + 583; illustrated; $£ 24$.) Eastbourne: W. B. Saunders. 1979.

Various complications can cause or contribute to the illness of burns and cause death. Consequently the treatment of those with large burns is much more than a matter of resuscitative fluid therapy and skin-grafting, important as these are. Though this volume seems primarily intended for surgeons, it contains material of interest to pathologists of various disciplines, especially chapters on the response to heat, skin pathology, metabolic effects, haematological changes, and aspects of burn scarring. Most of this is by clinicians with a scientific bent, and only two pathologists are identifiable among the multiple authorship. This no doubt reflects the scarcity of pathologists concerned with burns in the United States, a feature paralleled in Britain and elsewhere.

The basic theme is the need for a team approach to burned patients, a lesson previously stressed by Leonard Colebrook and more recently (1972) in the Report of the Working Party of the Royal College of Pathologists on The Pathology of Injury. All the many contributors are present or past members of the US Army Institute of Surgical Research in San Antonio, Texas, the home of the US Army Burns Center. The contents and the references quoted consequently reflect the strong influence which this centre has, and has had, in promoting the study and up-grading the treatment of burns in the United States. The volume is excellently produced and parts can be recommended to pathologists.

$$
\text { S. SEVITT }
$$

\section{Notices}

\section{International Society of Haematology}

The Joint Meeting of the 18th Congress of the International Society of Haematology and the 16th Congress of the International
Society of Blood Transfusion will be held on 16-22 August 1980 in Montreal, Canada. All enquiries should be addressed to: ISH/ISBT Congress-Montreal, 772 Sherbrooke Street West, Montreal, Quebec, Canada H3A 1G1.

VIth International Histo- and Cytochemistry Congress 1980

The VIth International Histochemistry and Cytochemistry Congress will be held in Brighton, UK, 17-22 August 1980. Further information from: Secretariat, VIth International Histochemistry and Cytochemistry Congress, Royal Microscopical Society, 37/38 St Clements, Oxford OX4 1AJ, UK.

4th International Congress of Immunology

Paris, France. 21-26 July 1980

Further information from CongrèsServices, 1, rue Jules-Lefèbvre-F-75009 Paris, France.

\section{9th International Symposium on Clinical} Enzymology

Verona, 17-20 April 1980

For information please write to: Prof. Angelo Burlina, Centro di Enzimologia Clinica, c/o Laboratorio di Patologia Clinica, Istituti Ospitalieri, I-37100 Verona-Italy.

\section{Correction}

A shortened scheme for the identification of indifferent streptococci by Sheena A. Waitkins, Lyn C. Ball, and Cherry A. M. Fraser. (January issue, page 47.)

In the section entitled Media on page 48 the following paragraph was omitted:

\section{Aesculin hydrolysis}

Trypticase Soy Broth (BBL) $\quad 15 \mathrm{~g}$

Aesculin

Ferric citrate

Agar

Distilled water

These were heated gently until thoroughly dissolved, the $\mathrm{pH}$ was then adjusted to $7 \cdot 5$, and the medium autoclaved at $15 \mathrm{lb}$ for 15 minutes. Aesculin hydrolysis was recognised by the blackening of the medium after five days' incubation. 